\title{
STEAM BOILERS AND ENGINES FOR HIGH PRESSURES.'
}

\author{
By Mr. Loftus Perkins, of London.
}

The object of this paper is to bring before the Institution plans for generating high-pressure steam, say from $250 \mathrm{lbs}$. to $1000 \mathrm{lbs}$. per square inch, and working it with great expansion and perfect safety, in conjunction with simplicity and durability. Sixteen years ago the author, conjointly with Professor Williamson, read a paper on this subject at a meeting of this Institution in 1861. The engine and boiler then described have been in use ever since, and recently becam $\theta$ the property of a gentleman who for several years has had another boiler and engine on the same system at work. The boiler and engine of 1861 are to be re-erected at the new works of the Sub-Wealden Gypsum Company, at Battle near Hastings, and are to form part of a steam plant consisting of three sets of boilers and engines, etc., on this system. Since 1861 many improvements have been effected, and are embodied in the engines recently constructed and illustrated in the accompanying diagrams.

In generating steam of the high pressure required to realize a fuller benefit of expansion, it has previously been found impossible to combine in the boiler great strength and safety with durability; if the former are secured, by reducing the internal dimensions and capacity of the boiler, the impurities passed in are fatal to the latter. In working a marine engine which was designed to use water distilled from sea-water, the author found that, although extreme care was taken to separate all the impurities from it before it was introduced into the boiler, the internal surfices were in the course of time seriously injured. In the same manner, ordinary marine boilers using surface condensation have been injured when there has been an insufficient supply of sea-water to form a protecting scale on the exposed internal surfaces. This led the author to seek for a remedy, which he succeeded in discovering, and adopted with absolute success. This was the use of nothing but fresh water, or distilled fresh water in the boiler, used over and over again, without any admixture of sea-water or the products of sea-water, and this was easily accomplished, as the

\footnotetext{
i Paper read before the Institution of Mechanical Engineers.
} 
machinery in question had been designed to avoid any leak whatever, and the amount of waste that did take place from glands, etc., was so small in quantity, that no practical inconvenience was found in providing the small supply of fresh water required to make good the waste that did occur.

The means taken to secure the soundness of all the joints and parts of the machinery were the same as those which had previously proved successful in the manufacture of the high-pressure heating apparatus which the author and his firm have been making for upwards of 45 years, and which has continued to work with the same water with which it was originally charged, without any destructive effect on the internal surfaces. Many sets of this heating apparatus have been working 40 years without decay; and some specimens of tubes from the boiler that was described in the former paper in 1861, which were cut out of this boiler for the Admiralty Boiler Committee in 1874, were found to be in such a remarkably good state of preservation that the committee made a special report on the system, which was laid before Parliament, and the specimens referred to are now shown on the table by the kind permission of the committee. The committee examined the condition of the boiler and cylinders of the engine at the writer's works, which were opened for the purpose, in the presence of the committee; and found the tubes of the boiler in a remarkably good state of preservation after having been in use nearly thirteen years, and the piston packing and valve rings made of the special metal were found in excellent condition after eighteen months' working without lubrication since last examined.

The possibility of using water which did not injure the internal surface of the boiler enabled the author to design the boiler on a system that combines maximum strength and safety. The horizontal tubes are $2 \frac{1}{4} \mathrm{in}$. internal and $3 \mathrm{in}$. external diameter, excepting the steam collecting tube, which is 4 in. internal and $5 \frac{1}{2}$ in. external diameter. The horizontal tubes are welded up at each end $\frac{1}{2}$ in. thick, and connected by small vertical tubes of $\frac{7}{8}$ in. internal and $1 \frac{5}{16}$ in. external diameter. The firebox is formed of tubes bent into a rectangular shape placed $1 \frac{3}{4} \mathrm{in}$. apart, and connected by numerous small vertical tubes $\frac{7}{8}$ in. internal diameter. The body of the boiler is made of a number of vertical sections, composed each of eleven tubes, connected at each end by a vertical one; these sections are connected at both 
ends by a vertical tube to the top ring of the firebox, and by another to the steam collecting tube. The whole of the boiler is surrounded by a double casing of thin sheet iron, filled up with regetable black to avoid loss of heat. Every tube is separately proved by hydraulic pressure to $4000 \mathrm{lbs}$. per square inch, and the boiler in its complete state to $2000 \mathrm{lbs}$, this pressure remaining in some hours without showing any signs of leakage. Experience of a very extensive character has proved that this construction of boiler can be worked safely, with great regularity, and without priming, and that the steam produced is remarkable for its freedom from moisture. The area through the vertical connecting tubes is found ample for allowing of the free escape of the steam, and for the prevention of injury from overheating of the tubes in contact with the flame. Injury arising from a prolonged stoppage of the feed supply is a casualty to which all boilers. are liable, but with this construction of boiler the small capacity of the sections reduces to a minimum any danger arising from such injury, and facilitates rapidity of repair.

The engine has three cylinders: the first is a single-acting highpressure cylinder, and the second also a single-acting cylinder, four times the capacity of the first; these two cylinders are bolted together in the same straight line, and have a common piston-rod. The third cylinder is double-acting, four times the capacity of the second, and its piston-rod is connected to a crank at right angles to the other crank.

Having safely generated steam of high pressure at say $350 \mathrm{lbs}$. per square inch, a serious difficulty has to be overcome in using it, from the high temperature affecting the lubrication of the pistons and packing of the glands. This difficulty the author has succeeded in overcoming by introducing the high-pressure steam into the upper end of the first cylinder, where there is no gland, and where the piston is formed so as to require no lubricating material. The steam is cut off at about half stroke in this cylinder, and when it is admitted for the return stroke into the bottom of the second cylinder, of four times the area, the temperature is so much reduced as to cause no difficulty when brought into contact with the piston-rod gland. From the bottom of the second cylinder the steam expands into the top of the same cylinder, which is of larger capacity than the bottom, and serves as a chamber, and is in direct communication with the valve box of the third cylinder; this last is double-acting, and is arranged to cut 
off at about a quarter strbke, and at the termination of the stroke exhausts into the condenser, with a total expansion of about thirtytwo times. All the cylinders are jacketed with wrought-iron tubes, which are cast in the metal, and supplied with steam direct from the boiler, the condensed water from the jackets being conveyed to the hot well. The whole of the cylinders and valve boxes, etc., are enclosed with a double case of thin sheet iron, filled in with vegetable black to prevent the escape of heat, and at the same time to maintain all the parts at a high temperature.

In working these high pressures with great expansion the ordinary mode of packing the pistons was found unsatisfactory, and to overcome the difficulty the compound piston was devised. The prevalent scoring and cutting of engine cylinders was effectually remedied by the discovery of the compound metal, of which the packing rings are made, which requires no lubricating.material. Many cylinders fitted with piston rings made of this metal have been several years at work, and have been often examined, the cylinders showing no signs of wear, the wear takes place on the rings only, which may be easily and inexpensively renewed as required, and experience has proved that with these pistons, the longer an engine is worked the more perfect does the surface of the cylinders become, and the less wear results to the packing rings. This metal for piston packing rings is composed of 5 parts tin and 15 parts copper, and has since been used by several other makers for ordinary engines with great success. When this metal is used, no oil or grease is required to lubricate the cylinders-a great advantage, particularly where the engines are fitted with surface condensers.

The high-pressure piston in the steamers Atacama and Coquimbo of the Pacific Steam Navigation Company were fitted with these packing rings, and it was reported by the superintendent engineer that the cylinders, which were previously rough and slightly grooved, were in the course of two or three voyages, or about 10,000 miles' run, brought up to a beautiful smooth surface, and had since kept in capital order, giving no trouble whatever. After having been once brought up to a smooth working surface, the packing rings did not wear the cylinders; the wear of the rings was also very slight, and the friction greatly reduced, and one-third of the lubrication necessary for cast-iron rings was found sufficient. In the torpedo vessels made for the French Government, Messrs. Thornycroft found these 
packing rings for the engine pistons a great advantage, as there was no chance of the cylinders being scored; and they were enabled to run the two hours' trial easily, at the high speed of about 430 revolutions per minute, without using any oil or grease in the cylinders. In an engine at the Dorking Grey Stone Lime Company's works, the manager reported, after 21 years' use of these packing rings for the piston, that they required no grease of any kind, and worked the cylinders to a polished face and needed no looking to until worn out; a set of rings lasted about 100 days, working at the usual high steam pressure of $400 \mathrm{lbs}$. per square inch.

The surface condenser used is constructed of a number of vertical tubes in such a manner as to be absolutely tight, so as to insure that the condensing water inside the tubes shall not mix with the water from the condensed steam outside them. The tubes are $\frac{7}{8}$ in. internal and $1 \frac{5}{16}$ in. external diameter, welded up at the top end and fixed securely in a tube plate at the bottom. These tubes are fitted with internal tubes, open at both ends, which are fixed in a division plate at the bottom, in order to cause the condensing water to circulate to their extreme ends.

A small still, worked by a steam coil, is used to distil water for replenishing any small waste that may take place in the feed supply. A duplicate apparatus forms part of the ordinary equipment of a sea. going vessel, to furnish steam from sea-water, for blowing the steam whistle, cooking, supplying distilled water for use of passengers and crew, and for all other purposes where distilled water is required.

In designing the machinery described, provision is made for passing any waste steam from the safety valves, etc., into the surface condenser, and the great strength of the boilers allows a margin of $100 \mathrm{lbs}$. per square inch or more to exist between the load on the safety valves and the pressure required to work the engines. When this system is fully carried out in steamships, the author would deem it quite safe, and more than ample for making good the waste of water from all sources, to provide, beyond the water in the boilers, a supply of fresh water in the proportion of 10 gallons per 24 hours per 100 indicated horse power. As an instance of the practical feasibility of carrying out the system of machinery that has been described, it may be stated that a boiler containing only 300 gallons, and an engine working at 250 lbs. pressure and 250 indicated horse power, were worked night and day continuously thirteen days (one Sunday excepted) without 
requiring any addition to make good the waste of working, nor at the end of the trial was there any appreciable difference in the water level of the boiler.

In the indicator diagrams exhibited, the two upper diagrams are taken from the working of a pair of marine engines on this plan of 70 nominal horse power, and the coal consumed averaged 1.62 lbs. per indicated horse power per hour. In this case there was no vacuum and no low-pressure cylinder, and the terminal pressure was $21 \mathrm{lbs}$. per square inch above the atmosphere; the boiler pressure was 300 lbs. per inch. With the addition of a low-pressure cylinder and a vacuum, the author considers it may safely be estimated that this system, properly carried out, will realize an average duty of one horse power for each pound of coal per hour.

\title{
A NEW METHOD OF COMPRESSING AIR.
}

\author{
By Jos. P. Frizell, C. E., Boston.
}

The memoir of M. Cornet in the June and July numbers of the JOURNAL, is a very complete exposition of the difficulties attending the use of compressed air as a vehicle for the transmission of power. I am glad to avail myself of this memoir as an introduction to what follows, since a reference to it relieves me of the necessity of going into physical discussion in pointing out a method of compressing air entirely free from the sources of loss arising from the development of heat, as well as others inherent in the use of mechanism.

Bubbles of air rise in still water with a very moderate velocity; the velocity depends upon the size of the bubble, increasing as the lafter increases, and this again depends upon the size of the orifice through which the air enters the water. From observations of my own, I find that bubbles issuing from an orifice of one-fourth of an inch diameter, do not rise faster than 15 inches per second in water of less than 20 feet depth. From depths of 50 feet the velocity is less than one foot per second. I assume in what follows that the average velocity in rising from depths of over 50 feet is one foot per second. This does not apply to great masses of air, such as rise when a diver is at work, Whouk No. Vole CIV.-(Terrd Series, Vol, 1xxiv.) 